\title{
Incidence of Escherichia coli 0157:H7 and E. coli Virulence Factors in US Bulk Tank Milk as Determined by Polymerase Chain Reaction ${ }^{1}$
}

\author{
J. S. Karns, ${ }^{\star 2}$ J. S. Van Kessel, ${ }^{*}$ B. J. McClusky, † and M. L. Perdue ${ }^{\star 3}$ \\ *Environmental Microbial Safety Laboratory, USDA-ARS, Beltsville, MD 20705 \\ †USDA Animal and Plant Health Inspection Service-Veterinary Services, Center for Epidemiology and Animal Health, Fort Collins, CO 80526
}

\begin{abstract}
Samples of bulk tank milk from dairies across the United States, taken as part of the National Animal Health Monitoring Dairy 2002 survey, were analyzed for the presence of several genes encoding virulence factors associated with enterohemorrhagic forms of Escherichia coli (EHEC) using real-time and conventional PCR assays. Samples from 859 farms in 21 states were collected and enriched in EC medium at $42.5^{\circ} \mathrm{C}$ to amplify any $E$. coli present, and DNA was isolated from the resulting biomass. The eaeA gene encoding intimin, a virulence factor associated with enteropathogenic forms of $E$. coli and EHEC, was detected in 199 (23\%) of the samples. Thirty-six samples $(4.2 \%)$ were positive for eaeA, the gamma allele of the translocated intimin receptor $(\gamma$-tir), found in EHEC strains of O157:H7, and one or both shiga-like toxin genes (stx1 and stx2), a combination that may be indicative of the presence of O157:H7 EHEC. Testing these 36 samples with a commercially available real-time PCR kit for detection of $\mathrm{O} 157: \mathrm{H} 7$ indicated that 5 samples could be contaminated with O157:H7. A multiplex PCR to detect the presence of $f l i C, r f b E$, and $h l y A$ genes found in O157:H7 reduced to $2(0.2 \%$ of all samples) the number of samples likely to be contaminated with this organism. A strain of 0157:H7 $\left(e a e A^{+}, \gamma-t i r^{+}, s t x 2^{+}, r f b E^{+}\right.$, $\mathrm{fliC}^{+}, h l y \mathrm{~A}^{+}$) was subsequently isolated from one sample. Thirty-four eaeA-positive samples did not contain detectable $\gamma$-tir but did contain one or both of the stx genes suggesting the presence of EHEC strains other than 0157:H7. These results indicate a low incidence of $\mathrm{O} 157: \mathrm{H} 7$ in bulk tank milk but suggest that a risk
\end{abstract}

\footnotetext{
Received January 5, 2006.

Accepted March 10, 2007.

${ }^{1}$ Mention of a trade name, proprietary product, or specific equipment does not constitute a guarantee or warranty by the USDA, and does not imply its approval to the exclusion of other products that may be suitable.

${ }^{2}$ Corresponding author: karnsj@ba.ars.usda.gov

${ }^{3}$ Present address: Dept. for Communicable Disease Surveillance and Response, Global Influenza Programme, World Health Organization (WHO/CDS/CSR/GIP), Geneva, Switzerland.
}

from other enteropathogenic and EHEC forms of $E$. coli may exist and that PCR targeting virulence factors associated with highly pathogenic forms of $E$. coli may be an effective means of detecting potential dangers in raw milk.

Key words: enterohemorrhagic Escherichia coli, foodborne disease, polymerase chain reaction

\section{INTRODUCTION}

Prevention of foodborne illness is a global concern that affects all aspects of food production, including dairy. Dairy cattle are known reservoirs for zoonotic bacteria and milk and milk products have been implicated in outbreaks of foodborne illness (Wells et al., 1991; Zhao et al., 1995; Wallace, 1999). These outbreaks are generally caused by improperly pasteurized products, postpasteurization contamination, or by raw milk and raw milk products. Salmonella is probably the most common human pathogen associated with dairy products but other bacteria such as Listeria monocytogenes, Yersinia spp., Campylobacter spp., and pathogenic Escherichia coli are also present in dairy production environments and have been associated with milk and milk products (Ryser, 2001; Woteki and Kineman, 2003). Although milk can be contaminated with bacterial pathogens via shedding in the udder, these zoonotic pathogens are not commonly associated with mastitis. Fecal contamination is considered to be the most common route of bulk tank milk contamination with these organisms.

Escherichia coli live commensally in the gastrointestinal tract of most mammals, including humans, without causing disease. However, a small fraction of $E$. coli are human pathogens and have been implicated in foodborne illness with increasing frequency over the last 2 decades. Ingestion of enteropathogenic $E$. coli (EPEC) can result in a mild gastrointestinal disease that is relatively self-limiting but a subset of the EPEC, enterohemorrhagic $E$. coli (EHEC), can cause hemolytic-uremic syndrome (HUS), a serious, potentially fatal illness (O'Brien and Kaper, 1998). The most common human clinical EHEC isolated in the United States is 
Table 1. Regions and states surveyed in the study

\begin{tabular}{llc}
\hline Region & \multicolumn{1}{c}{ States } & Samples, $\mathrm{n}$ \\
\hline West & California, Colorado, Idaho, New Mexico, Texas, Washington & 176 \\
Midwest & Illinois, Indiana, Iowa, Michigan, Minnesota, Missouri, Ohio, Wisconsin & 359 \\
Northeast & New York, Pennsylvania, Vermont & 263 \\
Southeast & Florida, Kentucky, Tennessee, Virginia & 61 \\
\hline
\end{tabular}

O157:H7 (Banatvala et al., 2001; Woteki and Kineman, 2003). Ground beef, a major by-product of the dairy industry, has been frequently associated with outbreaks of $E$. coli $\mathrm{O} 157: \mathrm{H} 7$ and milk-related outbreaks have also been reported, although these are less common (USDA:APHIS, 1997; Woteki and Kineman, 2003). The milk outbreaks were due to consumption of raw milk or milk that was contaminated postpasteurization (Ryser, 2001).

Escherichia coli $\mathrm{O} 157: \mathrm{H} 7$ has been frequently identified in cattle feces but, for the most part, adult cattle are asymptomatic shedders of this organism (DeanNystrom et al., 1999). As a result, identification of infected animals is difficult and there are no known mitigation methods to reduce or eliminate this organism from production environments. Therefore, it may be important from a public health standpoint to determine the prevalence of, and perhaps monitor the presence of, EHEC in the US raw milk supply. A few regional studies indicate that the prevalence of EHEC in bulk tank milk is relatively low. Shiga toxin-producing $E$. coli were detected in 3.8\% of bulk milk samples from South Dakota and Minnesota (Jayarao and Henning, 2001) and Steele et al. (1997) reported that $0.87 \%$ of bulk tank samples collected in Ontario contained verotoxigenic $E$. coli. The $E$. coli $\mathrm{O} 157: \mathrm{H} 7$ serotype was detected in $0.75 \%(2 / 268)$ of raw milk samples obtained from dairy farms in eastern Tennessee (Murinda et al., 2002).

Isolation of $E$. coli $\mathrm{O} 157: \mathrm{H} 7$ from a biological sample is often difficult due to the large background of nonpathogenic E. coli. Standard plating techniques that take advantage of differences in sorbitol fermentation or antibiotic resistance still yield numerous nonO157:H7 isolates. Additionally, O157:H7 is only one of several potential EHEC serotypes, so methods that are designed to look solely for this serotype may overlook other highly pathogenic serotypes. To our knowledge, there is no single molecular or immunological method that can detect low levels of EHEC in a sample, such as milk, with a diverse microbial population. Therefore, we have analyzed samples from a national survey of bulk tank milk for the presence of several virulence genes associated with EHEC using PCR with the objective of determining the incidence of EHEC O157:H7 in
US raw milk and to establish an idea of the levels of contamination by other EHEC serotypes.

\section{MATERIALS AND METHODS}

The milk samples used in this study were collected during the National Animal Health Monitoring System (NAHMS) Dairy 2002 survey. The states, the breakdown into regions for this study, and the number of samples from each region, are shown in Table 1 . The methods for collection, shipping, and analysis of bulk tank milk samples have been described previously (Van Kessel et al., 2004). For enrichment of E. coli, 5 to 10 $\mathrm{mL}$ of milk was added to $95 \mathrm{~mL}$ of EC medium (Difco, Detroit, MI). The variation in volume was due to variation in available sample. Enrichment bottles were incubated at $42.5^{\circ} \mathrm{C}$ for 14 to $18 \mathrm{~h}$. Two milliliters of the enrichment was centrifuged $(13,000 \times g, 2 \mathrm{~min})$, the supernatant removed, and the resulting pelleted material was suspended in $0.5 \mathrm{~mL}$ of a $1: 1$ mixture of the $2 \times$ freezing medium described by Schleif and Wensink (1981) and Lennox broth (Gibco Laboratories, Long Island, NY), and frozen at $-80^{\circ} \mathrm{C}$. To reculture a sample, the frozen material was thawed and mixed; $0.1 \mathrm{~mL}$ was removed and added to $5 \mathrm{~mL}$ of Lennox broth and the cells grown at $37^{\circ} \mathrm{C}$ overnight.

For PCR analysis, enriched samples $(1.5 \mathrm{~mL})$ were centrifuged $(13,000 \times g)$ in microcentrifuge tubes, the supernatants were discarded, and the pellets were stored frozen at $-20^{\circ} \mathrm{C}$. The DNA was extracted from the bacterial pellets using $200 \mu \mathrm{L}$ of InstaGene Matrix (BioRad Laboratories, Hercules, CA) following the manufacturer's directions. The DNA preparations were stored at $-20^{\circ} \mathrm{C}$ and were analyzed for the presence or absence of virulence genes associated with pathogenic E. coli via real-time or conventional PCR at a later date.

Immunomagnetic bead separation (IMS) was used to attempt to extract 0157:H7 from samples that were implicated by PCR analysis. One milliliter of recultured milk enrichment sample was centrifuged for $1 \mathrm{~min}$ at $13,000 \times g$ and the pellet suspended in $1 \mathrm{~mL}$ of PBS-2 [150 $\mathrm{m} M$ potassium phosphate $(\mathrm{pH} 7.2)$ and $150 \mathrm{mM}$ $\mathrm{NaCl}$. To this cell suspension was added $40 \mu \mathrm{L}$ of streptavidin beads (2.8 $\mu \mathrm{m}$; Dynalbeads M-280, Dynal A.S., Oslo, Norway) complexed to monoclonal anti-E. coli O157 antibodies (BioDesign International, Saco, ME). 


\section{DNA from EC enrichment biomass}

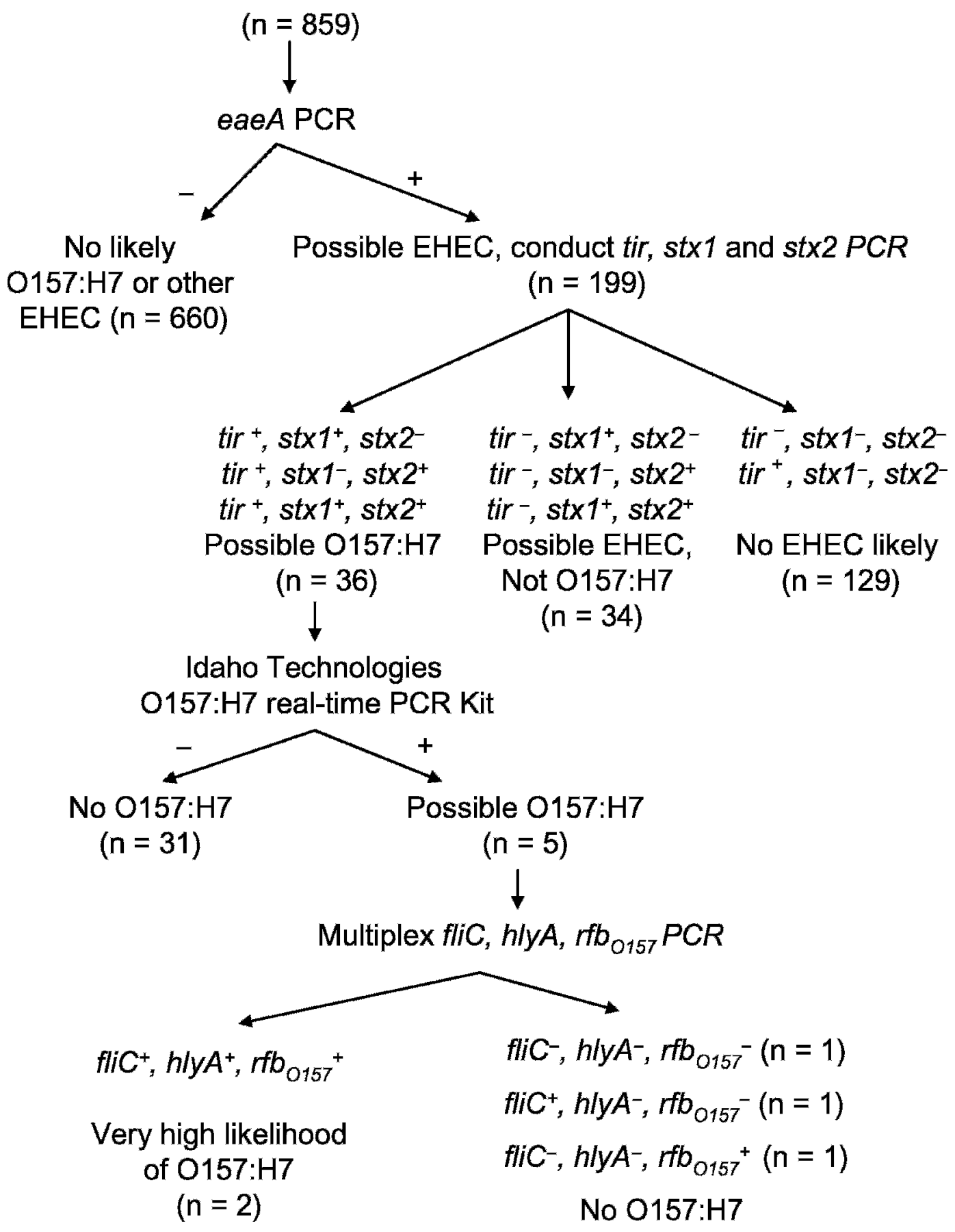

Figure 1. Schematic of the tiered PCR scheme used to detect virulence factors associated with Escherichia coli O157:H7 and other pathogenic $E$. coli in bulk tank milk.

The mix was incubated for $1 \mathrm{~h}$ at room temperature with shaking. This incubation mix contained approximately $10^{7}$ beads. Beads were condensed using a magnetized holder, suspended in $1 \mathrm{~mL}$ of PBS-2, and shaken for 15 min to dislodge poorly bound cells, extracted again, and resuspended in $1 \mathrm{~mL}$ of PBS-2. Then, $100 \mu \mathrm{L}$ was plated onto sorbitol-MacConkey agar plates containing cefixime and tellurite by using an Autoplate 4000 spiral plater (Spiral Biotech, Norwood, MA). Plates were incubated overnight at $37^{\circ} \mathrm{C}$. Sorbitol-nonfermenting colo- 
nies were further analyzed by plating on MacConkey, sorbitol-MacConkey, and Simmons citrate agars. Colonies that fermented lactose, but not sorbitol or citrate were considered potential O157:H7 isolates. Agglutination tests on presumptive isolates of $\mathrm{O} 157: \mathrm{H} 7$ were performed using a RIM $E$. coli O157:H7 latex test kit (Remel, Lenexa, KS).

A tiered PCR assay was used to examine nucleic acids extracted from enrichments of each milk sample for the presence of virulence factors associated with pathogenic forms of E. coli (Figure 1). All 859 samples were assayed with a TaqMan real-time PCR assay designed to detect all alleles of the eaeA gene encoding intimin. The eaeA gene sequence was extracted from an $E$. coli $\mathrm{O} 157: \mathrm{H} 7$ genome fragment in GenBank (Accession no. AF071034) and is the reverse complement of bp 16482 to 19286. The extracted O157:H7 sequence was compared with eaeA sequences from other $E$. coli serotypes using CLUSTAL W (Thompson et al., 1994). The primer/probe set was selected for a conserved region of $e a e A$ to detect a broad range of enterohemorrhagic and enteropathogenic $E$. coli. The primers JKP11 (GGCGATTACGCGAAAGATACC) and JKP12 (CCAGTGAACTACCGTCAAAGTTATTACC) are located at bp 550 to 570 and 685 to 658 , respectively, relative to the first base of the ATG codon representing the site of initiation of translation of the gene. The TaqMan probe JKTM10 (CAGGCTTCGTCACAGTTGCAGGC) is located at bp 592 to 614 .

All samples that yielded a positive result for eaeA were assayed for the presence of the gamma allele of the translocated intimin receptor $(\gamma-$ tir $)$ that is present in EHEC forms of E. coli O157:H7 (Nielsen and Anderson, 2003) and for the presence of the shiga toxin genes stx 1 and stx2. The tir sequence used to design the primers and probe is the reverse complement of bp 19954 to 21630 of GenBank sequence AF071034. This sequence was compared with tir sequences from other $E$. coli serotypes using CLUSTAL W and the primer/probe set was selected for a heterogeneous region of tir to detect only the $\gamma$ allele associated with $\mathrm{O} 157: \mathrm{H} 7$. The primers JKP1 (GTGGCGCATTGATTCTTGG) and JKP2 (CCGGCTGATTTTTTCGATGA) are located at bp 1097 to 1115 and 1144 to 1124 , respectively, relative to the first base of the ATG codon representing the site of initiation of translation of the gene. The TaqMan probe JKTM2Fr (CAGCGGTGACGGCAACACCAA) is located at bp 1168 to 1149 . The TaqMan assays used to detect the shiga-like toxin genes, stx 1 and stx 2 were those described by Sharma et al. (1999).

A TaqMan assay to detect the $\beta$-galactosidase gene (lacZ) of E. coli was designed using bp 1284 to 4385 extracted from GenBank Accession no. J01636. The primers JKP41 (GGGCCGCAAGAAAACTATCC) and
JKP42 (TCTGACAATGGCAGATCCCA) are located at bp 2715 to 2734 and 2785 to 2766 , respectively, relative to the first base of the ATG codon representing the site of initiation of translation of the gene. The TaqMan probe JKTM43 (CGCCTTACTGCCGCCTGTTTTGAC) is located at bp 2739 to 2762 . This assay was used as a PCR positive control to assure that there was no inhibition of PCR by substances in the nucleic acid extracts of enrichment cultures.

The eaeA, tir, and stx assays were performed using TaqMan Master Mix (Applied Biosystems, Foster City, CA) for $50 \mu \mathrm{L}$ reactions in an ABI 7700 Sequence Detector (Applied Biosystems) or a Stratagene MX4000 (Stratagene, La Jolla, CA) with $300 \mathrm{n} M$ of each primer and $250 \mathrm{n} M$ of probe. The $l a c Z$ assays were performed in a similar fashion except that $900 \mathrm{n} M$ of reverse primer (JKP42) was used. All PCR reactions also contained $50 \mu \mathrm{g} / \mathrm{mL}$ of BSA. The thermal program used on both instruments was $50^{\circ} \mathrm{C}$ for $2 \mathrm{~min}, 95^{\circ} \mathrm{C}$ for $10 \mathrm{~min}$, followed by 40 cycles of $95^{\circ} \mathrm{C}$ for $15 \mathrm{~s}$ and $60^{\circ} \mathrm{C}$ for $1 \mathrm{~min}$. Fluorescence data were obtained during the annealing and extension steps. A sample was considered positive when the fluorescence reading crossed a threshold value at an amplification cycle (Ct) earlier than a notemplate control. All primers and probes were obtained from Applied Biosystems. All probes were labeled with 6-FAM at the $5^{\prime}$-end and TAMRA at the $3^{\prime}$-end.

The O157:H7 detection kit from Idaho Technologies (Salt Lake City, UT) was used to further characterize samples that gave positive signals for eaeA and $\gamma$-tir using the Ruggedized Advanced Pathogen Identification Device (RAPID). Two microliters of sample was added to a $20-\mu \mathrm{L}$ reaction. Additional PCR analysis was done on select samples using multiplex primer set C described by Wang et al. (2002). Sequencing of the DNA was done on an ABI 3100 Genetic Analyzer using the PCR primers and Big Dye sequencing kits (Applied Biosystems).

Chi-square goodness of fit tests were used to test the hypothesis that virulence factors in raw milk were uniformly distributed across geographical region, and among samples with various somatic cell counts or degrees of coliform contamination. The GENMOD procedure of SAS (SAS Institute, Cary, NC) was used to analyze binomial distributed data with a logit-link function. The statistical model included linear and quadratic regression terms for SCC or coliforms on the logit scale.

\section{RESULTS}

Out of $E$. coli enrichments from 859 bulk tank milk samples taken from 21 states in the United States, 199 $(23.2 \%)$ were positive for the presence of the intimin 
gene (eaeA), indicating the presence of possible pathogenic forms of $E$. coli. Further examination of these 199 enrichments demonstrated that $36(4.2 \%)$ were also positive for the $\gamma$ allele of the translocated intimin receptor gene and one or both shiga-like toxin genes (stx1, stx2), indicating possible contamination with the EHEC O157:H7 strain of $E$. coli. Analysis of raw milk samples seeded with $0157: \mathrm{H} 7$ indicated that the detection limit for the PCR reactions was between 0.1 and 1 cell $/ \mathrm{mL}$ when single PCR reactions were run. The PCR of $l a c Z$ indicated there was no inhibition of amplification in any sample. Analysis of these $36 \mathrm{eaeA}^{+} t \mathrm{rr}^{+} s t x^{+}$samples with a commercially available PCR assay for detection of $\mathrm{O} 157: \mathrm{H} 7$ reduced the number of samples likely to have $\mathrm{O} 157: \mathrm{H} 7$ contamination to $5(0.6 \%)$. Examination of these 5 samples by conventional multiplex PCR indicated that only 2 samples $(0.02 \%)$ had a high probability of O157:H7 contamination based on the presence of the $r f b_{0157}$ (O157 serotype), $f i C$ (H7 flagellar serotype), and hlyA (EHEC hemolysin) genes. Culture of these samples after IMS to concentrate any O157:H7 led to the isolation of a sorbitol-nonfermenting, cefixime- and tellurite-resistant, eaeA $A^{+} t i r^{+} s t x 2^{+} r f b_{\mathrm{O}_{157}}{ }^{+} f i C^{+} h l y A^{+}$strain of $E$. coli from one sample. Agglutination assays confirmed that the strain was O157:H7.

It is important to note that PCR assays on EC enrichments detect the target genes in mixed cultures; thus, although the presence of O157:H7 would yield PCR reactions that were eaeA $A^{+} i r^{+} s t x^{+}$, the presence of these 3 genes in a sample is only suggestive of the presence of the organism. Detection by PCR of this or other combinations of eaeA and stx in the EC-enriched biomass of a milk sample may be suggestive of the presence of EHEC forms of E. coli other than O157:H7. The eaeA gene was detected in combination with one or both $s t x$ genes in 70 of the 859 bulk tank milk samples (8.1\%). Comparison of the incidence of the eaeA, stx, and $\gamma$-tir genes between samples from different regions of the United States is shown in Figure 2. The incidence of eaeA was highest in samples from the Western and Northeast regions and lowest in samples from the Midwest. Chi-square goodness-of-fit tests ( $\left.\chi^{2} \mathbf{G O F}\right)$ of uniform incidence indicated a lack of uniformity $(P=0.025)$ across regions for the incidence of eaeA in $E$. coli enrichments from bulk tank milk. The Midwest region also yielded a lower percentage of enrichment cultures with a combination of eaeA and stx than did the other 3 regions. In general, one or both of the stx genes was found in less than half of the samples that were eaeA positive. The $\chi^{2}$ GOF tests indicated a uniform distribution $(P=0.38)$ of stx across production regions of enrichments containing the eaeA gene. The combination of eaeA, $\gamma$-tir, and stx was also lower in the Midwestern region; however, $\chi^{2}$ GOF tests indicated that the distri-

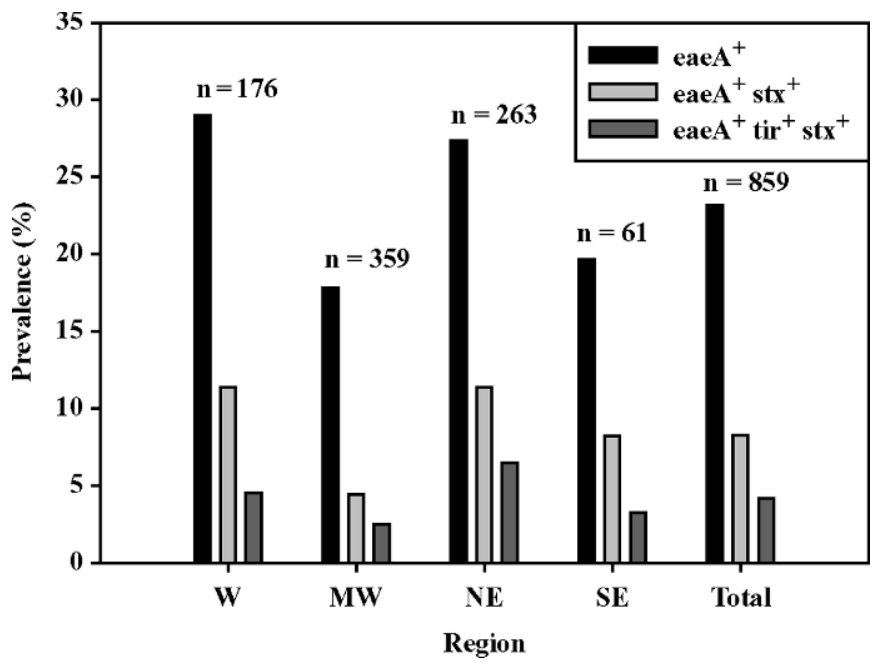

Figure 2.Prevalence of Escherichia coli virulence genes in DNA extracted from EC broth enrichments of bulk tank milk samples from NAHMS 2002 Dairy Survey by region. Shown is the incidence of all samples showing a positive PCR reaction for intimin (eaeA) and the subset of those samples that also contain one or both of the shigatoxin (stx) genes. The subset of $e a e A^{+} s t x^{+}$samples that also contained the $\gamma$-allele of the translocated intimin receptor $(\gamma$-tir $)$ is also shown. Regions: $\mathrm{W}=\mathrm{West} ; \mathrm{MW}=$ Midwest $\mathrm{NE}=$ Northeast $\mathrm{SE}=$ Southeast.

bution of enrichments containing these 3 factors was uniform $(P=0.58)$ across the regions.

Figure 3 shows the relationship between the prevalence of the 3 virulence genes in enrichments with the total coliform count determined for the original milk samples. Generally, a greater incidence of eaeA was

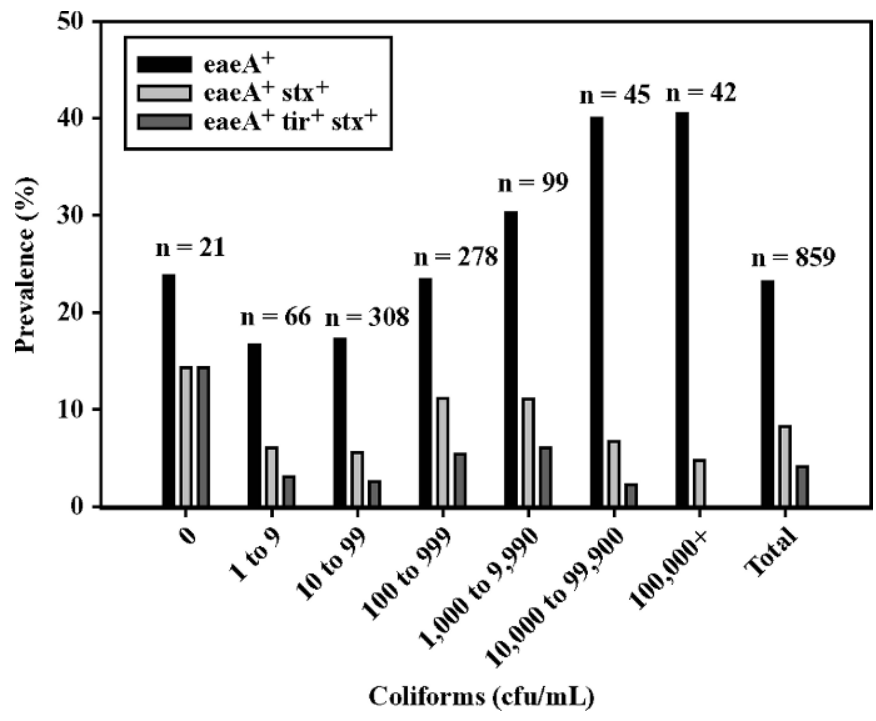

Figure 3. Prevalence of Escherichia coli virulence genes in DNA extracted from EC broth enrichments of bulk tank milk samples from NAHMS 2002 Dairy Survey vs. the number of coliform bacteria detected in a sample. 


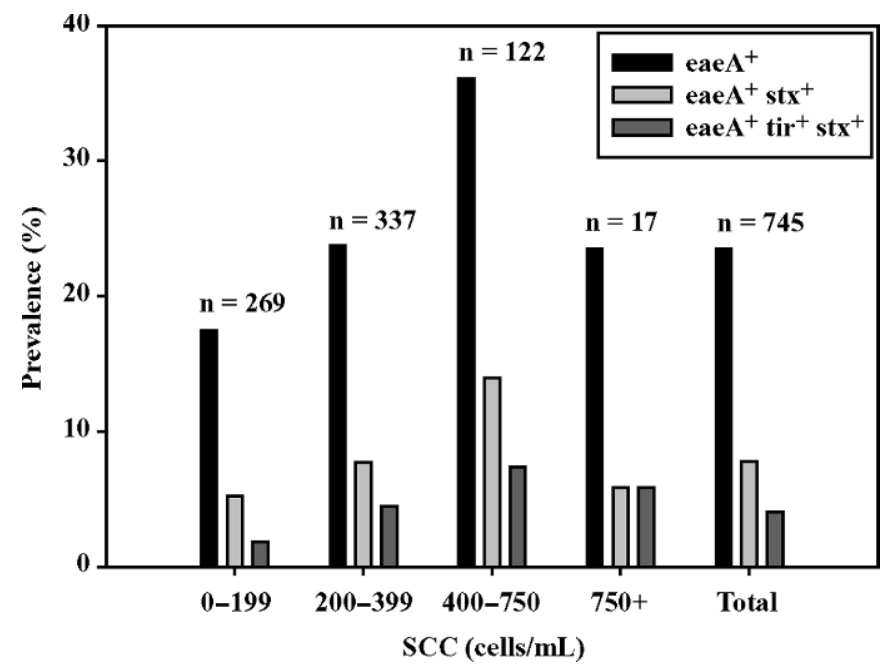

Figure 4. Prevalence of Escherichia coli virulence genes in DNA extracted from EC broth enrichments of bulk tank milk samples from NAHMS 2002 Dairy Survey, vs. the SCC determined for each sample.

seen in samples with higher coliform counts. No such trend was seen for combinations of eaeA and stx, or $e a e A$, stx, and $\gamma$-tir. The $\chi^{2}$ GOF tests indicated a significant lack of uniformity in the incidence of eaeA ${ }^{+}$ enrichments $(P<0.005)$ across coliform count categories whereas the distribution of eaeA $A^{+}$stx $^{+} \gamma$-tir ${ }^{+}$enrichments was somewhat more uniform $(P=0.08)$. The distribution of $e a e A^{+} s t x^{+}$enrichments appeared to be uniform $(P=0.22)$ across coliform count categories. The $\chi^{2} \mathrm{GOF}$ results were further supported by logistic regression performed using the GENMOD module (SAS Institute), which indicated a highly significant linear relationship $(P=0.0017)$ between coliform count and the presence of eaeA.

The relationship between SCC and the prevalence of $e a e A, s t x$, and $\gamma$-tir is shown in Figure 4. Samples with higher SCC generally were more likely to yield enrichment cultures in which the 3 virulence factors were detected. The $\chi^{2}$ GOF tests indicated a significant lack of uniformity in the distribution of eaeA $A^{+}(P=0.006)$ and eae $A^{+} \operatorname{stx}^{+}(P=0.040)$ enrichments across the SCC categories. The distribution of eaeA $A^{+} s t x^{+} \gamma-t i r^{+}$enrichments was somewhat more uniform $(P=0.077)$ over the SCC categories. Logistic regression confirmed a highly significant logit-linear relationship $(P=0.0031)$ between SCC and the presence of eaeA in enrichments and a significant logit-linear relationship between SCC and the incidence of eaeA $A^{+} s t x^{+} \gamma$-tir ${ }^{+}$enrichments $(P=$ 0.033).

To obtain an idea of the occurrence of the genes used for detection of $E$. coli O157:H7 in other milk samples, the multiplex PCR described by Wang et al. (2002) was run on 15 samples that did not seem to be contaminated with 0157:H7. Nine samples were $e a e A^{+} \gamma-t i r^{+} s t x^{+}$but were negative when tested with the Idaho Technologies O157:H7 kit; 4 samples were eaeA ${ }^{+} \gamma-$ tir $^{-}{ }^{-} t^{+}{ }^{+}$and were negative when tested with the Idaho Technologies O157:H7 kit; and 2 samples were $e a e A^{+} \gamma-t i r^{+} s t x^{-}$, with 1 showing a positive and 1 a negative result with the Idaho Technologies kit. The hlyA gene, indicating the presence of $E$. coli strains containing the EHEC plasmid, was found in 5 of these enrichments, all of which were $s t x^{+}$. The $f l i C$ gene encoding the flagellar protein responsible for the $\mathrm{H} 7$ serotype was found in 9 samples, one of which was $s t x^{-}$. None of these samples contained the $r f b_{\mathrm{O} 157}$ gene. One sample $\left(e a e A^{+} \gamma-t i r^{+}\right)$was $r f b_{\mathrm{O} 157}$ ${ }^{+}$and $\mathrm{fliC}^{+}$suggesting possible contamination by an O157:H7 strain but was stx and $h l y A^{-}$, suggesting an absence of any EHEC forms. The DNA sequences of the bands corresponding to the PCR products of $r f b_{\mathrm{O} 157}$, $f l i C$, and $h l y A$ extracted from agarose gels were identical (98\% or greater) to sequences of the corresponding O157:H7 genes.

\section{DISCUSSION}

The routine identification of pathogenic forms of $E$. coli in agricultural samples is complex and time consuming. Although methods for isolating EHEC O157:H7 exist, the isolation of the organism is generally more difficult with agricultural samples because the diversity of microorganisms often results in cross reactions. Identification of other EHEC serotypes is even more difficult because they lack the metabolic defect and antibiotic resistances found in $\mathrm{O} 157: \mathrm{H} 7$ strains. The use of PCR for the detection of virulence genes associated with pathogenicity in $E$. coli offers one way of determining the likelihood of contamination of a sample by pathogenic forms of $E$. coli regardless of serotype. In general, EHEC strains contain the locus of enterocyte effacement, of which eaeA is a part, and one or both shiga-like toxin genes. Thus, the detection of eaeA together with stx 1 or stx 2 in a milk sample could be considered suggestive of contamination by a pathogenic strain of $E$. coli. Because the survey described here was done on enrichments of the general coliform population in each sample, the PCR assays only indicate the presence of each gene within this population and do not discern whether the genes are present in a single, highly pathogenic form of $E$. coli. However, detection of these genes within this population should allow some assessment of the risks caused by these organisms in agricultural products.

Based upon this study, the incidence of EHEC O157:H7 in US bulk tank milk is very low. Only 2 of 859 samples $(0.02 \%)$ were shown to be contaminated by this organism by PCR and a culture was only ob- 
tained from 1 sample. However, the possibility of contamination by other EHEC serotypes is somewhat greater. The PCR assays on a subset of samples that did not appear to be contaminated with $\mathrm{O} 157: \mathrm{H} 7$ but were shown to contain both eaeA and stx genes showed that 5 of $13(38.5 \%)$ also contained hlyA, indicating potential for EHEC in those samples. Seventy-one of the 859 samples surveyed contained both eaeA and stx, and if $38.5 \%$ of them were $h l y A$ positive the potential exists for 27 samples to contain EHEC. The perfect set of PCR assays for assessment of EHEC risks associated with raw milk remains to be determined; in this study several confirmatory assays were required to detect samples that contained O157:H7. Based upon this study, initial assay for the presence of eaeA and stx genes followed by PCR detection of $h l y A$ in $e a e A^{+} s t x^{+}$ samples might be sufficient to suggest that a sample of raw milk may be contaminated with EHEC. However, there have been reports of an HUS-causing $E$. coli strain that lacks eaeA (Paton et al., 1999); although such a strain would be missed by the assays described herein, no such strain has been reported in cattle or in dairy products.

It is tempting to view the apparent relationships between SCC or coliform counts with the incidence of eaeA or eaeA-stx combinations in enrichments as signifying the potential for risk assessment through these easily measured parameters. Likewise, it is tempting to conclude that milk from certain regions may be less likely to contain pathogenic $E$. coli. However, of the 2 samples that were shown to contain O157:H7, one had a low coliform count of $16 \mathrm{cfu} / \mathrm{mL}$ but a high SCC of 761,000 cells/mL, whereas the other had a coliform count of $4,500 \mathrm{cfu} / \mathrm{mL}$ and a moderate SCC of 404,000 cells $/ \mathrm{mL}$. Additionally, one of these samples came from a farm in the Midwest, which had the lowest incidence of eaeA and eaeA stx containing samples. Thus, to our knowledge, no easily measured parameter adequately describes the risk from EHEC in milk.

Although contamination of dairy products currently accounts for a small percentage of foodborne illness in the United States, it is clear that raw milk consumption and the consumption of products made with raw milk presents some risk. Although proper pasteurization minimizes these risks to the public, there is a small but growing group of people that consume unpasteurized milk or milk products, either for practical (farm families) or cultural (soft ethnic cheeses) reasons, or because of perceived health benefits (Cody et al., 1999; Villar et al., 1999; Anonymous, 2002). This has lead to outbreaks of 0157:H7 diarrheal disease and HUS due to consumption of contaminated raw milk (Keene et al., 1997).
Although the incidence of $E$. coli $\mathrm{O} 157: \mathrm{H} 7$ in the milk samples tested here seemed to be very low $(0.02 \%)$, the populations of $E$. coli in a higher fraction of samples (8.3\%) contained a combination of virulence genes suggestive of other EHEC forms. In addition, $15 \%$ of the milk samples were contaminated by $E$. coli strains that may be milder pathogenic forms because they contain the eaeA gene. Because we only assayed eaeA-containing samples for the presence of the genes encoding stx 1 and stx2, we do not know the incidence of these toxin genes across all milk samples. The incidence of potentially pathogenic $E$. coli forms reported here, combined with the severity of the disease they can cause and the potential for this organism to grow in improperly stored raw milk and in products made from raw milk, means $E$. coli in raw milk represents a significant public health risk, particularly to more susceptible members of the population. There is evidence suggesting that the shedding of $0157: \mathrm{H} 7$ by cattle increases during summer months (Hancock et al., 1997; Van Donkersgoed et al., 1999; Dunn et al., 2004). The samples for this study were collected between March and June and therefore may underestimate the true prevalence of EHEC in bulk tank milk. Continuing surveys of milk will help estimate the true level of risk associated with these practices and may help to identify dairy management practices that minimize the contamination of bulk tank milk with zoonotic foodborne pathogens.

\section{ACKNOWLEDGMENTS}

We thank Thomas Jacobs Jr., Sumit Dua, and Claudia Lam for technical assistance.

\section{REFERENCES}

Anonymous. June 5, 2002. Got milk? The Washington Post, Washington, DC.

Banatvala, N., P. M. Griffin, K. D. Greene, T. J. Barrett, W. F. Bibb, J. H. Green, and J. G. Wells. 2001. The United States National Prospective Hemolytic Uremic Syndrome Study: Microbiologic, serologic, clinical, and epidemiologic findings. J. Infect. Dis. 183:1063-1070

Cody, S. H., S. L. Abbott, A. A. Marfin, B. Schulz, P. Wagner, K. Robbins, J. C. Mohle-Boetani, and D. J. Vugia. 1999. Two outbreaks of multidrug-resistant Salmonella serotype Typhimurium DT104 infections linked to raw-milk cheese in Northern California. J. Am. Med. Assoc. 281:1805-1810.

Dean-Nystrom, E. A., B. T. Bosworth, A. D. O'Brien, and H. W. Moon. 1999. Bovine infection with Escherichia coli O157:H7. Pages 5158 in Escherichia coli O157:H7 in Farm Animals. C. S. Stewart and H. J. Flint, ed. CABI Publishing, New York, NY.

Dunn, J. R., J. E. Keene, and R. A. Thompson. 2004. Prevalence of shiga-toxigenic Escherichia coli in adult dairy cattle. J. Am. Vet. Med. Assoc. 224:1151-1158.

Hancock, D. D., D. H. Rice, L. A. Thomas, D. A. Dargatz, and T. E. Besser. 1997. Epidemiology of Escherichia coli 0157 in feedlot cattle. J. Food Prot. 60:462-465.

Jayarao, B. M., and D. R. Henning. 2001. Prevalence of foodborne pathogens in bulk tank milk. J. Dairy Sci. 84:2157-2162. 
Keene, W. E., K. Hedberg, D. E. Herriott, D. D. Hancock, R. W. McKay, T. J. Barrett, and D. W. Fleming. 1997. A prolonged outbreak of Escherichia coli O157:H7 infections caused by commercially distributed raw milk. J. Infect. Dis. 176:815-818.

Murinda, S. E., L. T. Nguyen, S. J. Ivey, B. E. Gillespie, R. A. Almeida, F. A. Draughon, and S. P. Oliver. 2002. Prevalence and molecular characterization of Escherichia coli O157:H7 in bulk tank milk and fecal samples from cull cows: A 12-month survey of dairy farms in east Tennessee. J. Food Prot. 65:752-759.

Nielsen, E. M., and M. T. Anderson. 2003. Detection and characterization of verotoxin-producing Escherichia coli by automated 5' nuclease PCR assay. J. Clin. Microbiol. 41:2884-2893.

O'Brien, A. D., and J. B. Kaper. 1998. Shiga toxin-producing Escherichia coli: Yesterday, today, and tomorrow. Pages 1-11 in Escherichia coli $\mathrm{O} 157: \mathrm{H} 7$ and other shiga toxin-producing $E$. coli strains. J. B. Kaper and A. D. O'Brien, ed. ASM Press, Washington, DC.

Paton, A. W., M. C. Woodrow, R. M. Doyle, J. A. Lanser, and J. C. Paton. 1999. Molecular characterization of a shiga toxigenic Escherichia coli O113:H21 strain lacking eae responsible for a cluster of cases of hemolytic-uremic syndrome. J. Clin. Microbiol. 37:3357-3361.

Ryser, E. T. 2001. Public Health Concerns, Pages 397-545 in Applied Dairy Microbiology. E. H. Marth and J. L. Steele, ed. Marcel Dekker Inc., New York, NY.

Schleif, R. F., and P. C. Wensink. 1981. Practical Methods in Molecular Biology. Springer-Verlag, New York, NY.

Sharma, V. K., E. A. Dean-Nystrom, and T. A. Casey. 1999. Semiautomated fluorogenic PCR assays (TaqMan) for rapid detection of Escherichia coli O157:H7 and other shiga toxigenic E. coli. Mol. Cell. Probes 13:291-302.

Steele, M. L., W. B. McNab, C. Poppe, M. W. Griffiths, S. Chen, S. A. Degrandis, L. C. Fruhner, C. A. Larkin, J. A. Lynch, and J. A. Odumeru. 1997. Survey of Ontario bulk tank raw milk for food-borne pathogens. J. Food Prot. 60:1341-1346.
Thompson, J. D., D. G. Higgins, and T. J. Gibson. 1994. CLUSTAL W: Improving the sensitivity of progressive multiple sequence alignment through sequence weighting, position-specific gap penalties and weight matrix choice. Nucleic Acids Res. 22:4673-4680.

USDA:APHIS. 1997. An update: Escherichia coli O157:H7 in humans and cattle. CEAH, Fort Collins, CO.

Van Donkersgoed, J., T. Graham, and V. Gannon. 1999. The prevalence of verotoxins, Escherichia coli O157:H7, and Salmonella in the feces and rumen of cattle at processing. Can. Vet. J. 40:332-338.

Van Kessel, J. S., J. S. Karns, L. Gorski, B. J. McCluskey, and M. L. Perdue. 2004. Prevalence of Salmonellae, Listeria monocytogenes, and fecal coliforms in bulk tank milk on US Dairies. J. Dairy Sci. 87:2822-2830.

Villar, R. G., M. D. Macek, S. Simons, P. S. Hayes, M. J. Goldoft, J. H. Lewis, L. L. Rowan, D. Hursh, M. Patnode, and P. S. Mead. 1999. Investigation of multidrug-resistant Salmonella serotype Typhimurium DT104 infections linked to raw-milk cheese in Washington State. J. Am. Med. Assoc. 281:1811-1816.

Wallace, J. S. 1999. The ecological cycle of Escherichia coli O157:H7. Pages 195-223 in Escherichia coli O157 in Farm Animals. C. S. Stewart and H. J. Flint, ed. CABI Publishing, New York, NY.

Wang, G., C. G. Clark, and F. G. Rodgers. 2002. Detection in Escherichia coli of the genes encoding the major virulence factors, the genes defining the O157:H7 serotype, and components of the type 2 Shiga toxin family by multiplex PCR. J. Clin. Microbiol. 40:3613-3619.

Wells, J. G., L. D. Shipman, K. D. Greene, E. G. Sowers, J. H. Green D. N. Cameron, F. P. Downes, M. L. Martin, P. M. Griffin, and S. M. Ostroff. 1991. Isolation of Escherichia coli serotype O157:H7 and other shiga-like-toxin-producing $E$. coli from dairy cattle. J. Clin. Microbiol. 29:985-989.

Woteki, C. E., and B. D. Kineman. 2003. Challenges and approaches to reducing foodborne illness. Annu. Rev. Nutr. 23:315-344.

Zhao, T., M. P. Doyle, J. Shere, and L. Garber. 1995. Prevalence of enterohemorrhagic Escherichia coli O157:H7 in a survey of dairy herds. Appl. Environ. Microbiol. 61:1290-1293. 